\title{
PENGARUH PENGETAHUAN PRODUK, KEPERCAYAAN, PERSEPSI HARGA, DAN RISIKO YANG DIMILIKI TERHADAP MINAT BELI PRODUK TONGSIS “TONGKAT NARSIS” DI PAMERAN GADGET JOGJA EXPO CENTER (JEC)
}

\author{
Atika Putri Kinanthi \\ Atikakinanthi@yahoo.co.id
}

The purpose of this study was to describe product knowledge, trust, perceived price and perceived risk on the purchasing intention of Tongsis "Tongkat Narsis" in gadget exhibition Jogja Expo Center (JEC). This study classified as a insidental sampling reseach. Thew population is 100. Data collection using a questionnaire, while data analysis techniques using multiple regression analysis by T-Test, and the classical assumption test of normality test, heteroscedasticity and multicollinearity test.

The result showed the multiple linear regression model is $Y=$ 0,227XI+0,084X2+0,212X3-0,071X4+e. That is, product knowledge (X1), Trust (X2), Perceived price (X3), and perceived risk (X4) contributes greatly to the purchasing intention. The magnitude of the effect seen from the detemination coefficient (. Value of the determinant coefficient (. The result show that the coefficient determinant of product knowledge, Trust, Perceived Price and Perceived Risk have a positif influence on purchasing intention by $6,32 \%$ and the remaining $93,7 \%$ is influenced by other factors.

Keywords: product knowledge, Trust, Perceived Price, Perceived Risk and Purchasing Intention.

\section{PENDAHULUAN}

"SELFIE" (Self Potrait). Kata ini sudah tidak asing lagi didengar oleh masyarakat Indonesia yang artinya adalah memotret diri sendiri atau narsisme. Atau bisa juga diartikan sebagai pengambilan foto diri sendiri melalui kamera depan smartphone atau webcam yang kemudian diunggah ke social media. Tujuan selfie itu sendiri agar foto itu tertuju pada orang tersebut, biasanya orang yang suka selfie itu orang yang kurang percaya diri akan gaya foto orang tersebut, jadi orang tersebut lebih memilih selfie daripada meminta tolong orang lain untuk memfotokannya. Karena selfie sangat popular pada saat ini, alat-alat baru pun bermunculan seperti "Tongsis (Tongkat Narsis)", alat bantu yang sangat fenomenal. Bagaimana tidak? Dengan perangkat ajaib ini, kini orang-orang dimudahkan dalam ber-selfie, tidak perlu meminta bantuan orang lain untuk mengambil gambar.

Anindito Respati Giyardani atau sering disebut dengan "Babab" adalah orang Indonesia yang berhasil menciptakan alat ajaib ini, awalnya Babab hanya seorang penggila smartphone yang sudah lama tergabung dalam komunitas 


\section{JURNAL MANAJEMEN VOL. 5 NO. 2 DESEMBER 2015}

Iphonesia (kumpulan para pecinta Iphone), setelah Babab melihat kegemaran dari teman- temannya yaitu selfie namun kurang maksimal karena keterbatasan jangkauan tangan manusia. Babad akhirnya berinisiatif memodifikasi monopod dengan menyambungkan ujungnya dengan gagang penyangga untuk memasang perangkat smartphone. Selain itu alat ini mempunyai keunggulan yaitu dapat mengambil gambar dari sudut tinggi (high angle).(http://m.jpnn.com/news.php?id=2 44945).

Pengetahuan tentang produk,

\section{KAJIAN PUSTAKA}

\section{Niat Beli}

Pengertian niat beli itu sendiri menurut Basu Swastha (1993:251) yaitu mengidentifikasikan semua pilihan yang mungkin untuk memecahkan persoalan itu dan menilai pilihan-pilihan secara sistematis dan obyektif serta sasaransasarannya yang menetukan keuntungan serta kerugiannya masing-masing. Sedangkan menurut Philip Kotler (1998) bahwa perilaku konsumen menentukkan niat beli konsumen. Pemasar perlu memusatkan perhatian pada niat beli konsumen. Proses pembelian oleh konsumen merupakan sebuah pendekatan penyesuaian masalah yang terdiri dari 5 kepercayaan, risiko yang dimiliki dan persepsi terhadap harga ternyata membuat minat beli tongsis semakin meningkat. Karena minat beli merupakan sesuatu yang berhubungan dengan rencana konsumen untuk membeli produk tertentu, serta berapa banyak unit produk yang dibutuhkan pada periode tertentu. Semakin banyak minat beli untuk produk tongsis ini, semakin banyak pula terdapat senyum bahagia dari tiap konsumen karena mereka merasa puas akan hasil foto yang diperoleh dengan bantuan tongsis tersebut.

tahap yang dilalui konsumen, kelima tahap tersebut adalah : pengenalan kebutuhan, pencarian informasi, evaluasi berbagai alternatif, keputusan pembelian dan perilaku pasca pembelian.

\section{Pengetahuan Produk}

Pengetahuan produk adalah kumpulan berbagai macam informasi mengenai produk. Pengetahuan ini meliputi kategori produk, merk, terminology produk, atribut atau fitur produk, harga produk dan kepercayaan mengenai produk (Sumarwan,2002). Pengetahuan produk meliputi berbagai informasi yang diproses oleh konsumen untuk memperoleh suatu produk. Menurut Engel, Blackwell, dan Miniard (1995) 
pengetahuan produk dapat dipilah-pilah seperti pengetahuan tentang toko, lokasi produk di dalam toko tersebut dan penempatan produk di dalam toko. Suatu produk akan memberikan manfaat kepada konsumen jika produk tersebut telah digunakan atau dikonsumsi oleh konsumen. Agar produk tersebut dapat memberikan manfaat yang maksimal dan kepuasan tinggi kepada konsumen, maka konsumen harus bisa menggunakan atau mengkonsumsi produk tersebut dengan benar. Oleh karena itu, ada beberapa produk yang melampirkan buku petunjuk pada produknya karena kekeliruan dalam penggunaan produk bukan hanya dapat mengecewakan konsumen tetapi juga dapat mempercepat kerusakan produk.

\section{Kepercayaan}

Kepercayaan dimana pembeli percaya bahwa pemasok memiliki keahlian untuk melakukan aktivitas secara efektif dan handal. Kepercayaan berhubungan dengan niat perusahaan untuk mengandalkan mitra pertukaran mereka. Selain itu kepercayaan sebagai sebuah kebajikan, karena didasarkan pada sejauh mana perusahaan percaya bahwa mitranya memiliki niat dan motif-motif yang menguntungkan. Seperti yang dikatakan oleh Morgan dan
Hunt (1994, dalam Maima, 2012) kepercayaan pada dasarnya adalah "komponen sentral dalam semua hubungan pertukaran".

Perusahaan yang memiliki reputasi yang baik yaitu yang iklan-iklannya cenderung dipercaya oleh audiens, masyarakat cenderung lebih mudah menerima merk perusahaan, demikian pula logo perusahaan juga lebih mudah dikenali, dan pada gilirannya konsumen menjadi lebih loyal. Sementara itu hasil penelitian dari Taylor \& Hunter (2003 dalam Maima, 2012) menunjukkan bahwa kepercayaan memiliki pengaruh positif terhadap sikap konsumen.

\section{Persepsi Harga}

Dari sudut pandang produsen, harga merupakan satu-satunya unsur bauran pemasaran yang memberikan pemasukan atau pendapatan bagi perusahaan, sedangkan ketiga unsur lainnya (produk, tempat, dan promosi) menyebabkan timbulnya biaya atau pengeluaran. Harga bisa diungkapkan dengan berbagai istilah, misalnya iuran, sewa, bunga, upah dan sebagainya. Dari sudut pandang pemasaran, merupakan satuan moneter atau ukuran lainnya yang ditukarkan agar memperoleh hak kepemilikan atau penggunaan suatu barang atau jasa (Tjiptono, 1997). 


\section{JURNAL MANAJEMEN VOL. 5 NO. 2 DESEMBER 2015}

\section{Risiko yang Dimiliki}

Risiko yang dimiliki adalah proses di mana seorang konsumen menerima, mengenali dan memahami rangsangan yang datang pada dirinya, lewat inderaindera yang ada dan menimbulkan perasaan bahwa keputusan minat akan membeli produk yang dibuatnya memiliki kemungkinan mendatangkan konsekuensi yang tidak menyenangkan.

\section{HIPOTESIS}

H1 : Semakin tinggi pengetahuan produk konsumen semakin tinggi juga minat

\section{METODOLOGI}

Penelitian ini dilakukan di pameran gadget Jogja Expo Center (JEC). Populasi dalam penelitian ini adalah pengunjung pameran gadget Jogja Expo Center (JEC) yang berminat membeli Tongsis "Tongkat Narsis". Dalam penelitian ini responden yang dipilih

\section{HASIL DAN PEMBAHASAN}

Hasil dari regresi berganda dalam penelitian ini menunjukan bahwa variabel bebas (X) yang digunakan dalam penelitian ini hanya mempengaruhi variabel terikat (Y) sebesar 0,063 (6,3\%). Hal ini menunjukan bahwa 93,7 \% faktor lain yang dapat mempengaruhi Minat Beli Tongsis "Tongkat Narsis" di pameran beli terhada Tongsis "Tongkat

Narsis".

$\mathrm{H} 2$ : Semakin tinggi kepercayaan konsumen semakin tinggi juga minat beli terhadap Tongsis

"Tongkat Narsis".

H3 : Semakin tinggi persepsi harga konsumen semakin tinggi juga minat beli terhadap Tongsis "Tongkat Narsis".

H4: Semakin tinggi risiko yang dimiliki konsumen semakin turun minat beli

terhadap Tongsis “Tongkat Narsis".

adalah konsumen yang berminat untuk membeli produk Tongsis "Tongkat Narsis". Variabel dependen yang digunakan adalah minat beli. Variabel independen terdiri dari pengetahuan produk, kepercayaan, persepsi harga dan risiko yang dimiliki. Untuk lebih jelasnya akan digambarkan dalam kerangka pikir.

gadget Jogja Expo Center (JEC). Berdasarkan tabel persamaan regresi dari penelitian ini adalah sebagai berikut:

$$
\begin{aligned}
& Y=-\mathbf{0 , 2 2 7 X 1 + 0 , 0 8 4 X 2 + 0 , 2 1 2 X 3 - ~} \\
& 0,071 X 4+e \text {. }
\end{aligned}
$$

Hasil pengujian hipotesis 1 menunjukan bahwa X1 (Pengetahuan Produk) mempengaruhi Y (Minat Beli), 
dengan menggunakan tingkat signifikansi 5\% $(\mathrm{a}=0,05)$, dan diperoleh 1,6606. Dari perhitungan SPSS 16.0 dihasilkan sebesar $-2,282$ sehingga $(-2,282<1,6606)$. Dengan koefisien sebesar $-0,227$ dan tingkat signifikansi $0,025>0,05$ yang artinya variabel Pengetahuan Produk berpengaruh terhadap Minat Beli.

Hasil pengujian hipotesis 2 menunjukan bahwa X2 (Kepercayaan) tidak mempengaruhi Y (Minat Beli), dengan menggunakan signifikansi 5\% $(\mathrm{a}=0,05)$, dan diperoleh 1,6606. Dari perhitungan SPSS 16.0 dihasilkan sebesar 0,801 sehingga $(0,801<1,6606)$. Dengan koefisien sebesar 0,082 dengan tingkat signifikansi $0,425>0,05$ yang artinya variabel Kepercayaan tidak berpengaruh terhadap Minat Beli.

Hasil pengujian dari hipotesis 3 menunjukan bahwa variabel X3 (Persepsi Harga) mempengaruhi Y (Minat Beli), dengan menggunakan tingkat signifikansi $5 \%(a=0,05)$, dan diperoleh 1,6606. Dari perhitungan SPSS 16.0 dihasilkan sebesar 2,159 sehingga $(2,159>1,6606)$. Dengan koefisien sebesar 0,212 dengan tingkat signifikansi $0,033<0,05$ yang artinya variabel Persepsi Harga sangat berpengaruh terhadap Minat Beli.

Hasil pengujian dari hipotesis 4 menunjukan bahwa variabel X4 (Risiko yang Dimiliki) tidak mempengaruhi $\mathrm{Y}$ (Minat Beli), dengan menggunakan signifikansi $5 \%(\mathrm{a}=0,05)$, dan diperoleh 1,6606. Dari perhitungan SPSS 16.0 dihasilkan sebesar $-0,710$ sehingga ($0,710<1,6606)$. Dengan koefisien sebesar 0,071 dengan tingkat signifikansi 0,479>0,05 yang artinya variabel Risiko yang Dimiliki tidak berpengaruh terhadap Minat Beli.

\section{KESIMPULAN}

Dapat disimplkan dari keempat variabel bebas tersebut dua diantaranya berpengaruh terhadap minat beli yaitu variabel pengetahuan produk dan persepsi harga sedangkan dua variabel lainnya tidak berpengaruh terhadap minat beli yaitu variabel kepercayaan dan risiko yang dimiliki. Sumbangan dari variabel Pengetahuan Produk (X1), Kepercayaan (X2), dan Persepsi Harga (X3), dan Risiko yang Dimiliki (X4) terhadap Minat Beli (Y) sebesar 0,063 atau 6,3 \%. Dan masih ada faktor lainnya yang mempengaruhi Minat Beli Tongsis "Tongkat Narsis" di pameran gadget Jogja Expo Center (JEC) sebesar $93,7 \%$. 


\section{JURNAL MANAJEMEN VOL. 5 NO. 2 DESEMBER 2015}

DAFTAR PUSTAKA

Akdeniz, Aybeniz, 2011., "Effect Of Perceived Values On The Brand Preference And The Purchase Intention". European Scientific Journal, Vol.8,No.17.

Aydin Gulnil, 2014., "The Role Of Brand Trust On Parents Purchase Intentions Of Baby Care Products". Dogus Universitesi Dergisi, 15 (2). No.165180.

Baek, Tae Hyun and Jooyoung Kim, 2010., "The Differential Roles Of Brand Credibility And Brand Prestige In Consumer Brand Choice". Psychology \& Marketing, Vol. 27 (7), 662-678.

Basu, Swastha, 2000., Manajemen Penjualan cetakan ke-duabelas, Liberty Yogyakarta, Yogyakarta.

Bian Xuemei, 2011., "The Role Of Brand Image, Product Involvement, and Knowledge In Explaining Consumer Purchase Behaviour Of Counterfeits". Eouropean Jurnal of Marketing, Vol.45, Nol-2.

Chang, Hsin Hsin and $\mathrm{Su}$ Wen Chen, 2008., "The Impact Of Onine Store Environment Cues On Purchase Intention Trust and Perceived Risk as a Mediator". Online Information Review, Vol. 32 No.6.

Chiu, Chao-Min, 2012., "Understanding Customers Repear Purchase Intention In B2C E-Commerce: The Roles Of Utilitarian Value, Hedonic Value, and Perceived Risk". Info Systems Journals, Vol:24, No. 85-114. 10

Lee, Yi-Chih, 2014., "The Effect Of WordOf-Mouth, Knowledge, And Promotions On Purchase Intention Of Medical Cosmetics". International
Journal Of Organizational Innovation, Vol.5,No.3.

Parasuraman., 1996, Service marketing, research methodology, sales management, JM 8, JMR 4, JR 5, JAR 1, others 56.

Philipp „Phile Klausa., 2013. “Towards a Better of Customer Experience". International Journal of Market Research, Vol.55 Issue 2.

Philip kotler., 2002, edisi 3 . Dasar-dasar pemasaran Penerbit intermedia.

Santoso, Singgih, 2000., "Buku Latihan SPSS Statistic Parametrik, Jakarta. Penerbit media Komputindo.

Stemvelt, Robert C. diterjemahkan oleh Purwoko., 2004, Perception of Service Quality Massachusetts : Allyn and Bacon

Stanton, W.J., 1996, Prinsip Pemasaran, Jilid II, Edisi 7, Jakarta. Penerbit Glora Aksara Pratama.

Statist, Pak. J., 2011., "Effect Of Consumer Environmental Attitude On Green Consumption DecisionMaking”. Pakistan Jornal Of Statistics, Vol. 27 (5), 699-708.

Sugiyono, 2013, Metode Penelitian Kuantitatif Kualitatif Dan $R \& D$, Bandung. 11 Penerbit Alfabeta.

Sumarwan, francis tantric, 2012., Manajemen Pemasaran, Jakarta Penerbit Raja Grafindo Persada.

Sutrisno Hadi. 2001. Thesis Metodologi Research untuk Penulisan Paper, Skripsi, dan Disertasi, Jilid Tiga.Yogyakarta. Penerbit Andi.

Uma sekaran., 2005, Metode penelitian untuk bisnis, edisi empat,Jakarta. Penerbit salemba empat.

Udayana, I.B.N, 2013., "Membuat tabel Statistik Dengan SPSS”, Yogyakarta. 


\section{JURNAL MANAJEMEN VOL. 5 NO. 2 DESEMBER 2015}

Chou, Chieh-Min, 2013., "Factors Affecting Purchase Intention Of Online Game Prepayment CardEvedence From Thailand". Journal Of Internet Banking And Commerce, Vol.18, No.3.

Ghazali, Imam, 2011, Aplikasi Analisis Multivariate dengan Program IBM
SPSS 19, Semarang. Penerbit BP. UNDIP.

Kotler, Philip., 1995, Manajemen Pemasaran, Perencanaan dan Pengendalian, edisi keenam, Jakarta. Penertbit Erlangga. 
JURNAL MANAJEMEN VOL. 5 NO. 2 DESEMBER 2015 